\title{
USE OF A ROLEPLAYING EXERCISE TO ILLUSTRATE DESIGN STAKEHOLDER ROLES IN A FIRST-YEAR DESIGN COURSE
}

\author{
Juan Abelló, Alys Avalos-Rivera, Saloome Motavas, Vladan Prodanovic, Sandra Zappa-Hollman \\ University of British Columbia \\ abello@mech.ubc.ca, alys.avalos@ubc.ca
}

\begin{abstract}
VANT 150 is a first-year course in design and sustainability for international students enrolled in the Vantage One program at UBC. One of its learning outcomes is to understand the importance of communication between different stakeholders in the design process.

The 2016 final exam revealed that students had difficulties understanding the positions of the designer, client and user as stakeholders. A simulation (roleplaying) exercise was implemented in 2017 in order to help students better understand these roles and raise awareness about the importance of communication between them.

The 2016 and 2017 final exams included a question to differentiate stakeholder roles. We found that the average score in this question was 8\% higher in 2017 than in 2016. This difference is statistically significant with $p<0.005$. This suggests the stakeholder simulation activity helped our students better understand these concepts.
\end{abstract}

Keywords: International student, design, stakeholder, simulation, roleplay.

\section{INTRODUCTION}

The increasing population of international students accepted to Canadian universities [1] poses complex challenges for students and instructors in engineering programs. One of these challenges simultaneously involves refining linguistic survival skills in a second language and acquiring the specialized terminology and communication practices of a specific professional community. Overcoming these communication barriers is often daunting, even for those students with strong background in hard sciences and mathematics, disciplines usually perceived as essential to achieve success in engineering. Understandably, these tensions are particularly threatening during the first year of undergraduate education, when international students deal also with all the social and psychological pressures associated to the experience of studying abroad [2], [3].
To support incoming students during this transition period, Vantage College at the University of British Columbia offers a program that provides embedded academic English instruction linked to the core engineering courses that students take during their first year [4].

In the context of the Vantage One engineering program, VANT 150 is a three-credit, yearlong core course in design and sustainability. It consists of one hour of lecture each week followed by two hours of tutorial, which give students the opportunity of practicing design concepts through different activities in the form of group assignments and mini-projects. Students enrolled in VANT 150 receive additional language instruction through VANT 140, a three-credit, yearlong course designed to support students' disciplinary-specific language development through content-specific tasks.

As part of the coordinated work of engineering and language instructors in the courses described above, a number of content-based instructional units were identified as especially challenging for students in previous academic years [5]. One of these units focused on the role of stakeholders (users, clients, and designers) in the design process, and the importance of communication between them. (In the context of design, clients are entities that wish to sell a solution to the user, and designers are hired by the clients in order to devise a solution for the need of the users [6].) As selfexplanatory as these terms may seem, evidence from the VANT 150 final exam in 2016 suggested that students' lacked full comprehension of the terms. In spite of the explanations provided during the weekly lectures, the difference between the broader meaning of words such as "user" and "client" and their conceptually-loaded meaning when used as terms specific to engineering design was unclear for students. In response to this issue, an experiential approach to teach the same unit was implemented: a simulation exercise in which students assume various roles in a fictive stakeholders' meeting, and discuss the outcomes of the design based on the requirements proposed by each stakeholder group. 


\section{BACKGROUND}

The use of simulation and gaming for instructional purposes has been widely applied in diverse disciplines since the mid twentieth century [7], [8]. Although the original definition of simulation has evolved over the decades, in essence it still refers to as a series of contextrich learner-centered tasks in which the participants embody well-defined roles. Unlike role-plays, which engage participants in impromptu acting situations, simulations provide learners with rich information regarding the setting as well as the positions and motivations of each character [9]. This emphasis on building the participants' ownership of the context and content-knowledge related to the simulation [10] leads to the development of pre-tasks that expose the learners to multimodal material (e.g., readings, lectures, videos, among others) before the final performance takes place. It is therefore not surprising that researchers have found that the gap between reading comprehension, speaking, and writing can be often bridged by engaging secondlanguage learners in simulations [7]. Previous studies also concur that simulations may provide learners with a relatively stress-free and meaningful learning environment in which they can apply discipline specific contents and develop language skills simultaneously [11][13]. These benefits, highlighted by recent applications of simulation tasks to language content-based education in other disciplines [14], [15], encouraged our team to implement a series of simulations to better support student learning in our design course. The present paper reports the results on the first of these efforts.

\section{METHODS}

We introduced a simulation exercise on the first VANT 150 tutorial after the first week of lecture. Before coming to the tutorial, students had seen in lecture a definition of the user, client and designer stakeholder roles, and the importance of communication between them for correct problem formulation. We also presented a sample conversation between user and client to illustrate how interaction between user and client helps better formulate the need statement. This content was based on similar methods followed by Hyman [6].

Once in the tutorial, students were divided into five design teams of 4-5 students each. Roles of user, client and designer were assigned to different members of each team, so that each team had at least one student representing each role. Students were then given worksheets corresponding to their particular role. One side of the worksheets was common for all roles, and contained the need statement ("I need a safer way to carry my phone than in my back pocket because my phone breaks often if I carry it that way") and a brief description of each stakeholder role. The other side of the worksheets was different for each role, and contained instructions for the particular role to follow. (These worksheets appear in appendix A.)

Once stakeholder roles had been assigned, students broke from their design groups and formed one group for each stakeholder role. Each group had a different activity according to their worksheet. Users imagined a story that inspired the need statement provided, and listed five requirements that the product must meet. Clients formulated five questions for the users in order to clarify the need statement, and listed five of their needs as a manufacturing company that the designers should know. Designers wrote five questions for the users and five for the clients in order to clarify their needs. Students discussed in their stakeholder groups and agreed on common statements to write in their worksheets.

Students then returned to their original design groups, which contained at least one representative of each stakeholder role. Users shared their need story with the clients, clients asked their questions to the users, and designers asked their questions to the users and clients. Students on each group then decided whether to modify the initial need statement to better reflect their discussion, and then proposed an improved need statement. Each group shared their improved need statement with the class, and the instructors led a brief discussion on the importance of communication between stakeholder roles.

\section{RESULTS}

\subsection{Classroom behavior}

We observed this to be a dynamic activity that held the interest of the students during a one-hour tutorial. It took some instructor guidance to set the exercise in motion, after which students participated actively in the discussion. Although not requested in the worksheets, some designers proposed solution ideas and shared them with the rest of the class at the end of the exercise. The instructors then asked students to imagine themselves as investors, and evaluate whether to invest in the proposed solution.

\subsection{Final exam performance}

The 2016 and 2017 final exams included a question to measure student understanding of the user, client and designer stakeholder roles. The text of the 2016 and 2017 final exam questions were essentially the same. The topics were comparable (products familiar to the general public, and whose purpose is known to the students), the length of the questions was similar, and the assigned marks and instructions were identical in both exams. The question was written and marked by the same instructor in both years. The 2016 final exam was unreleased, so 2017 students did not have access to this type of question before taking the exam. 
The average student score this question was $84 \%$ in 2016 and $92 \%$ in 2017. This shows an increase of $8 \%$ in average score for 2017 . This difference is statistically significant with $p<0.005$. We believe this reflects students better understanding the design stakeholder roles following the incorporation of our roleplay exercise.

A histogram presenting question scores in 2016 and 2017 appears in figure 1. This figure shows that the percentage of students scoring in the $90-100 \%$ bracket increased from $54 \%$ in 2016 to $74 \%$ in 2017 . This indicates the number of students scoring $\mathrm{A}+$ in this question increased by $20 \%$.

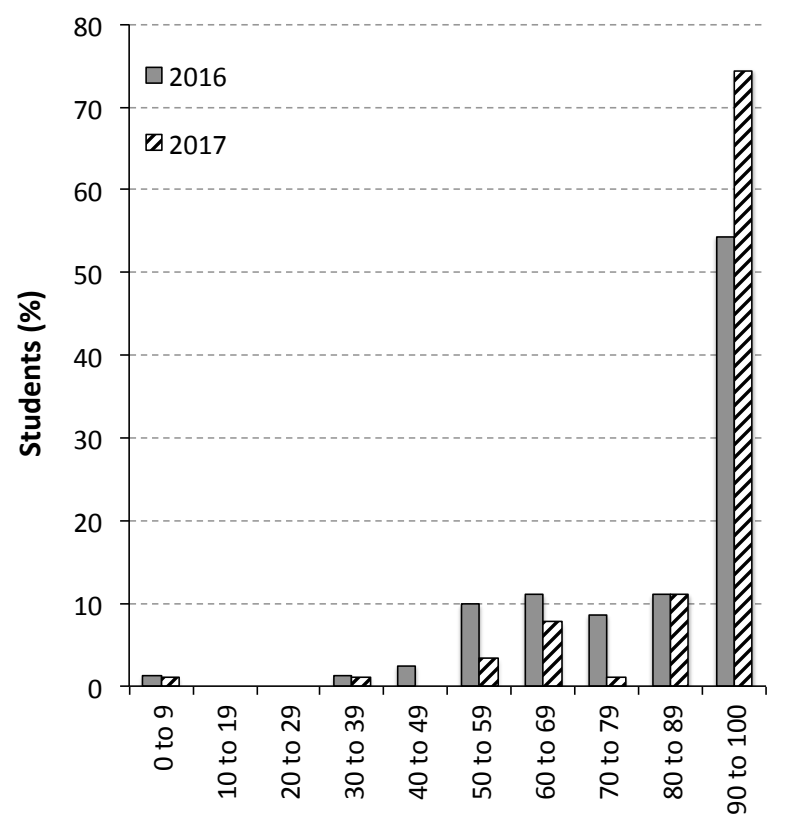

Stakeholders question score (\%)

Figure 1: Histogram of the stakeholders question score.

We also found that, during the exam, several 2016 students asked for clarification about stakeholder roles, while no student asked us for clarification during the 2017 exam.

\section{CONCLUSIONS}

Implementing a simulation exercise to help students understand the user, client and designer stakeholder roles in the design process yielded positive results in our class. The final exam average on a question relevant to this material increased by $8 \%(\mathrm{p}<0.005)$ and the percentage of students scoring $\mathrm{A}+$ in this question increased by $20 \%$. The simulation activity required presenting relevant concepts in lecture beforehand and instructor guidance during tutorial, but once students understood its steps they participated actively and seemed to enjoy the experience. Our preliminary experience suggests that simulation exercises may be useful to explain stakeholder concepts in engineering design, particularly to students who are also learning English during their first-year undergraduate program. More rigorously-designed studies would be required to explore this link further.

\section{References}

[1] C. Thomson and V. M. Esses, "Helping the Transition: Mentorship to Support International Students in Canada," J. Int. Students, vol. 6, no. 4, pp. 873-886, 2016.

[2] H. C. Gallagher, "Willingness to Communicate and Cross-cultural Adaptation: L2 Communication and Acculturative Stress as Transaction," Appl. Linguist., vol. 341, pp. 53-73, 2013.

[3] C. Kinginger, "Identity and Language Learning in Study Abroad."

[4] "Engineering | UBC Vantage College." [Online]. Available: https://vantagecollege.ubc.ca/engineering. [Accessed: 06-May-2018]

[5] S. Motavas, L. Hellwig, and V. Prodanovic, "Integration of English Language Modules into the Introduction to Engineering Design Course in the Vantage College 1st year Engineering Program at the University of British Columbia," Proc. 2017 Can. Eng. Educ. Assoc. Conf., 2017.

[6] B. I. Hyman, Fundamentals of Engineering Design, 2nd ed. Prentice Hall, 2002.

[7] A. Cheng, "Simulation-based L2 writing instruction: Enhancement through genre analysis," Simul. Gaming, vol. 38, no. 1, pp. 67-82, 2007.

[8] D. Crookall, "The founding of modern simulation/gaming and ISAGA four decades on," Simul. Gaming, vol. 43, no. 1, pp. 5-14.

[9] K. Jones, Simulations: A Handbook for Teachers and Trainers, Rev. ed. London: Kogan Page, 1995.

[10] B. Moder, C. L., Seig, M. T. D., Van Den Elzen, "Cimarron valley: a simulation-based EAP Composition curriculum," Simul. Gaming, vol. 33, pp. 284-298, 2002.

[11] T. G. Saliés, "Promoting Strategic Competence: What Simulations Can Do for You," Simul. Gaming, vol. 33, pp. 280-283, 2002.

[12] R. Oxford and D. Crookall, "Research on Language Learning Strategies: Methods, Findings, and Instructional Issues," Mod. Lang. J., vol. 73, no. 4, pp. 404-419, Dec. 1989.

[13] D. Crookall and R. Oxford, Simulation, gaming and language learning. New York: Newbury House Publishers, 1990.

[14] H.-Y. A. Chang, L. Chan, and B. Siren, "The impact of simulation-based learning on students' English for Nursing Purposes (ENP) reading proficiency: A quasi- 
experimental study," Nurse Educ. Today, vol. 33, pp. 584-589, 2013.

[15]

M. Dostal, "Developing foreign language communicative competence for English Business meetings using business meeting simulations," $\mathrm{Scr}$. Manent, vol. 11, pp. 2-20, 2016.

\section{APPENDIX A: STAKEHOLDER WORKSHEETS}

All students received a worksheet. One side of the worksheet was the same for all stakeholder roles, and presented instructions for the exercise. The other side of the worksheet was different for each role.

\subsection{Instructions handout}

1. Users meet in one table. Clients meet in another table. Designers meet in another table. Each of them completes their corresponding part 1.

2. Teams meet in separate tables. Each team completes their corresponding part 2.

Need statement: I need a safer way to carry my phone than in my back pocket because my phone breaks often if I carry it that way.

\section{Part 1}

Users: you are the consumers of the product that the clients will present to you.

Your tasks are:

- Imagine and write a story that inspired the need statement.

- Make a list of 5 requirements that the product must meet.

Clients: you manage a manufacturing company that wishes to sell a solution to the users. You decided to hire the designers because you have no engineering experience.

Your tasks are:

- Write a list of 5 questions for the users so that you clarify their need.

- Write a list of 5 things that the designers needs to know about your needs as a manufacturing company.

Designers: you are consulting engineers hired by the clients to design a solution for the need statement.

Your tasks are:

- Write a list of 5 questions for the users so you clarify their need.

- Write a list of 5 questions for the clients so you clarify their needs.
Part 2

Users: tell the designers and clients your story that inspired the need statement.

Clients: ask your questions to the users. Write their answers.

Designers: ask your questions to the users. Write their answers.

Designers: ask your questions to the clients. Write their answers.

Users, designers and clients: do you need to modify the need statement to better reflect your discussion? If so, write an improved need statement.

\subsection{User worksheet}

Users: you are the consumers of the product that the clients will present to you.

Your story that inspired the need statement:

Your list of 5 requirements that the product must meet.

1.

2.

3.

4.

5.

Modified need statement (if applicable):

\subsection{Client worksheet}

Clients: you manage a manufacturing company that wishes to sell a solution to the users. You decided to hire the designers because you have no engineering experience.

Your list of 5 questions for the users so that you clarify their need.

1.

Answer: 
2.

Answer:

3.

Answer:

4.

Answer:

5.

Answer:

Your list of 5 things that the designers needs to know about your needs as a manufacturing company.

1.

2.

3.

4.

5.

Modified need statement (if applicable):

\subsection{Designer worksheet}

Designers: you are consulting engineers hired by the clients to design a solution for the need statement.

Your list of 5 questions for the users so that you clarify their need.
1.

Answer:

2.

Answer:

3.

Answer:

4.

Answer:

5.

Answer:

Your list of 5 questions for the clients so you clarify their needs.

1.

Answer:

2.

Answer:

3.

Answer:

4.

Answer:

5.

Answer:

Modified need statement (if applicable): 